\title{
Bloom’un yenilenmiş taksonomisine göre bir sınav analizi
}

Fahrettin Korkmaz

Milli Eğitim Bakanlığı, Gaziantep, Türkiye, korkmaz2725@gmail.com

\author{
Serkan Ünsal
}

Kahramanmaraş Sütçüimam Üniversitesi, Eğitim Fakültesi, Kahramanmaraş, Türkiye, serkanunsal@ksu.edu.tr

ÖZ Bu çalışmada 2013 Kamu Personeli Seçme Sınav (KPSS)’ında Tarih Öğretmenliği Alan Bilgisi Testinde yer alan soruların yenilenmiş Bloom Taksonomisinin bilgi ve bilişsel süreç boyutlarına göre analizi amaçlanmıştır. Araştırma sürecinde nitel araştırma yöntemlerinden doküman analizi tercih edilmiştir. Bu yöntem kapsamında 2013 yılı Tarih Öğretmenliği Alan Bilgisi Testinde yer alan 50 sorunun düzeyi Yenilenmiş Bloom Taksonomisine dayalı ölçütlere göre hazırlanan tabloya yerleştirilmiştir. Yerleştirme işleminin sonuçları esas alınarak, 2013 KPSS Tarih Öğretmenliği Alan Bilgisi Testindeki sorular bilgi boyutuna göre incelendiğinde soruların 31 tanesinin (\% 62) olgusal bilgi; 12 tanesinin (\%24) kavramsal bilgi; 6 tanesinin (\%12) işlemsel bilgi; 1 tanesinin (\%2) ise üst bilişsel bilgiyi ölçmek üzere hazırlanmış olduğu görülmektedir. Bilişsel süreç boyutuna ilişkin ise $31(\% 62)$ sorunun bilginin hatırlama boyutunu; 12 (\%24) sorunun anlama boyutunu; 4 (\%8) sorunun uygulama boyutunu; 1 (\%2) sorunun analiz etme boyutunu; $2(\% 4)$ sorunun ise değerlendirme boyutunu ölçmek üzere hazırlandı̆̆ı tespit edilmiştir.

Anahtar

Kelimeler

Tarih öğretimi, taksonomi, yenilenmiş Bloom taksonomisi

\section{Analysing a test based on Bloom's revised taxonomy}

ABSTRACT This study aims to evaluate questions of proficiency test in History teaching posed in the Public Personnel Selection Examination (2013) in accord with knowledge dimension and cognitive process dimension of Bloom's revised taxonomy. Being one of the qualitative research methods, document analysis was employed during the study. Accordingly, level of fifty questions posed in the test in concern were tabulated with respect to the criteria of Bloom's revised taxonomy. When evaluated based on the knowledge dimension, it is revealed that 31 out of 50 questions (62\%) were posed to assess phenomenal knowledge, 12 (24\%) of them cognitive knowledge, 6 of them (12\%) operational knowledge, and 1 of them (2\%) higher cognitive knowledge. As for the cognitive process dimension, 31 of the questions $(62 \%)$ were designed to assess retrieving dimension of the knowledge, $12(24 \%)$ understanding dimension, $4(8 \%)$ application dimension, $1(2 \%)$ analysis dimension, and $2(4 \%)$ evaluation dimension.

Keywords History teaching, taxonomy, Bloom's revised taxonomy 


\section{EXTENDED SUMMARY}

The cognitive based taxonomy developed by Bloom and colleagues has sustained its effectiveness for almost 50 years (Pickard, 2007). However, 3 cognitive science experts, 3 curriculum educational programs and teaching experts, 2 evaluation and assessment experts, a total of 8 educators, and a group of researchers arranged meetings during 1995-2001 to make a revision on Bloom's Taxonomy; by coming to an agreement about the taxonomy requiring a revision, David Krathwohl and Lorin Anderson pioneered the revision (Anderson, 2005; Krathwohl, 2002). According to Bümen (2006) there are two primary reasons for the update in Bloom's Taxonomy. The first of these is finding solutions for the problems concerning the problems with designs, practices and strategies by shifting educational workers' attractions to the original taxonomy; and the second is uniting the taxonomy with recent information gathered from the USA and other regions throughout the world.

There are many national and international studies conducted on the Revised Bloom's Taxonomy. Various examples of national studies are: Bümen's (2006)Breakthrough in Program Development: The Revised Bloom's Taxonomy, the Examination of Science Course Written Exam Questions According to the Revised Bloom's Taxonomy study conducted by Tanık and Saraçoğlu (2011), Evaluation of Grammar Acquisitions from Turkish Course books according to the Revised Bloom's Taxonomy conducted by Eroğlu and Kuzu (2014), Comparison of Written Exam Questions and ÖSS Exam Questions According to Revised Bloom's Taxonomy conducted by Köğce and Baki (2009). Among the international studies, there is Krathwohl's (2002) study on revising Bloom's Taxonomy; Anderson's (2005) study on goal evaluations and educational development; Amer's (2006) study on the reflections of the Revised Bloom's Taxonomy; Pickard's (2007) study on the Revised Bloom's Taxonomy. The fact that there are very rare studies on Public Personnel Selection Examination (KPSS), which is a crucial exam in Turkey, can be considered as a deficiency. The aim of this study is to fulfill this deficiency and serve as a starting point.

The purpose of this study is to determine the distribution of the 2013 KPSS History Teaching Content Knowledge Test questions within the knowledge and cognitive process dimensions of the Revised Bloom's Taxonomy. The question, what is the distribution of the 2013 KPSS History Teaching Content Knowledge Test questions according to the Revised Bloom's Taxonomy? was directed.

The qualitative research model was used in this study; and the document analysis method was adopted. Document analysis; involves analyzing written materials that contain information about events and facts and can be used as a method in educational studies (Yıldırım and Şimşek, 2010).

Written documents containing the 2013 KPSS History Teaching Content Knowledge Test questions were used as the data collection instruments in the study.

The questions of the 2013 KPSS History Teaching Content Knowledge Test were examined according to the Revised Bloom's Taxonomy. The table, developed by Krathwohl (2002), which contains the knowledge and cognitive process dimension of the revised taxonomy was used in the data analysis process. The questions were examined and which cognitive process dimension each question was placed under was determined; then, which stage of the knowledge dimension they were placed under was identified. The name section in each question was placed under the knowledge dimension; the verbal section was placed under the cognitive process dimension. Based on the opinions of Bekdemir and Selim (2008), in cases where the test questions signified more than one dimension at the same time with regards to the cognitive process dimension, they were placed to a higher rank category. Then the findings gathered from 50 History questions were placed in the table developed by Karthwohl (2002). The stages of the questions on The Revised Bloom's Taxonomy's knowledge and cognitive process dimensions were determined according to the table. The frequency and percentage values of the tests' distributions were identified. Examples of how the questions of the KPSS History Teaching Content Knowledge Test were analyzed are given below.

When the 2013 KPSS History Teaching Content Knowledge Test questions are considered based on the knowledge dimension, it is evident that 31 questions (62\%) are about phenomenal knowledge; 12 (24\%) about conceptual knowledge; $6(12 \%)$ about operational knowledge and $1(2 \%)$ about metacognitive knowledge. When the phenomenal knowledge dimension is examined based on the cognitive process dimension, it is evident that $12(24 \%)$ questions are at the remembering; $4(8 \%)$ at the understanding; 2 (4\%) at the analyzing and $2(4 \%)$ questions are at the evaluating dimension. When the conceptual knowledge dimension is examined based on the cognitive process dimension, it is evident that $5(42 \%)$ 
questions are at the remembering; $6(50 \%)$ at the understanding; $1(17 \%)$ question is at the analyzing dimension. When the operational knowledge dimension is examined based on the cognitive process dimension, it is evident that $1(17 \%)$ question is at the remembering; $4(66 \%)$ questions are at the applying and $1(17 \%)$ question is at the evaluating dimension. When the operational knowledge dimension is examined based on the cognitive process dimension, it is evident that $1(17 \%)$ question is at the remembering; $4(66 \%)$ questions are at the applying and $1(17 \%)$ question is at the evaluating dimension. When the metacognitive dimension is considered based on the cognitive process dimension, it is evident that $1(100 \%)$ question is at the evaluation dimension. When the questions of the 2013 KPSS exam regarding the Department of History Teaching is examined according to the knowledge and cognitive process dimensions of the Revised Bloom's Taxonomy, over half of the questions (31 questions) are at the "remembering", the lowest section, of the cognitive process dimension and there are no applying, analyzing and evaluating stages that measure high level thinking skills which can be regarded as a deficiency. Although there are many questions concerning the "remembering" dimension; there were only one questions concerning the cognitive processes of the analyzing and evaluating dimensions which suggests that there is a proportional inconsistency in the distribution of questions. The fact that the total number of History Teaching questions on understanding, applying, evaluating and synthesizing are less than the questions on "remembering" concerning the cognitive process dimension can be regarded as a discrepancy. 


\section{GİRIŞ}

Tarih; geçmişte yaşanan olgu ve olaylardan hareketle bugünü anlama/anlamlandırma çabası ve bugünden yola çıkarak geleceği şekillendirmemize yardımcı olan bir disiplin olarak tanımlanabilir. Tarih; Şıvgın (2009)'a göre Batı'da daha çok hatırlanmaya değer olayların hikâyesi anlamında kullanılmaktadır. Sosyal bir gerçeklik olarak tarih, dar anlamıyla insanoğlunun geçmişte yaşadığı gerçekliği; geniş anlamıyla ise sosyal bir varlık olarak insanın geçmişte yaşadığı, şu an yaşanılan ve gelecekte yaşanılacak olanın bütününü ifade eder.

Toplulukların tarihe yönelik ilgisi ilkçağda Heredot'tan bu yana farklı şekillerde, dönemsel olarak artmış azalmış ancak hiçbir zaman yok olmamıştır. Toplumların tarihe yönelik ilgisinin arka planında yatan gerekçeler ise şu anı anlamlandırmak, siyasi, ideoloji, kültürel olarak düşünceleri temellendirmek ve meşru kılmak; grupları bir arada tutmanın gereği olarak ortak bir bilinç oluşturmak olarak sıralanabilir (Gutek, 2006). Duygu, düşünce ve davranışlarımız bilinçli ya da bilinçsiz şekilde tarihten etkilenir veya şekillenir. Bugünü oluşturan her ne varsa geçmişin izlerini taşır ve bizim nasıl düşüneceğimiz ya da nasıl davranacağımızı farklı şekillerde etkiler (Aslan, 2006; Şıvgın, 2009). Bu bağlamda tarih öğretimi duygu, düşünce ve davranışlarımızı etkilediğinden ve şekillendirdiğinden dolayı önemli görülmektedir. Tarihi önemli kılan nedenlerden biri de tarihsel çizginin herhangi bir döneminde bulunan toplulukların kendi kültür ve değerlerini geçmişten geleceğe taşıma arzusu; tarihsel bir sürekliliğe sahip olma kaygısı olarak da düşünülebilir. Toplumlar kendi varlıklarını devam ettirmek, var olan değerlerini gelecek kuşaklara aktarmak için tarih önemli bir fonksiyon icra etmektedir. Çünkü tarih var olan kültürün ve değerlerin önemini geçmişle ilişkilendirerek açıklamaya çalışırlar.

\section{Tarih öğretimi ve KPSS}

Tarih öğrenimi sayesinde birey bir yandan güncel olaylar geçmişle bağlantısını kurarak geniş açıdan değerlendirirken diğer yandan da toplumsal olayları farklı şekillerde düşünme becerisi kazanır. Tarih ögrenimi toplumsal faydaları açısından değerlendirildiğinde bireylere milli değer, kültür ve bilincin kazandırılmasında, geçmişte yapılan hatalardan ders çıkartılarak, geleceği inşa etme sürecinde fayda sağlamaktadır. Tarih öğreniminin evrensel anlamda faydaları ise var olan kültürleri insanlığın ortak mirası olduğu düşünüldüğünde bu ortak mirasın nasıl ortaya çıktığı hangi aşamalardan geçerek meydana geldiğinin bilincine vardırılması olarak da değerlendirilebilir (Okur, Genç, Özcan, Yurtbay, Sever, 2014).

Tüm disiplinlerde olduğu gibi tarih içinde sorulması gereken soruların başında "Neden Tarih Öğretiyoruz?" sorusu gelmektedir. Söz konusu bu durum içinde bulunan zamana, koşullara ve ülkelere göre farklılık göstermektedir. Bununla birlikte Aslan (2006)'a göre tarih öğretimi genel olarak aşağıdaki amaçları gerçekleştirmek için öğretilmektedir:

1. İnsanlığın farklı zamanlarda geçirdiği değişim/dönüşümleri görmek,

2. İnsanlığın ortak kültürel mirasının kavranması ve çağa uygun kimlik oluşumunun sağlanmak,

3. Bilişsel kapasitenin geliş̧irilmesine olanak sağlamak,

4.İnsani, vicdani ve moral kapasitenin geliştirilmesine olanak sağlamak amaciyla tarih öğretilmektedir. Tarih disiplini içerinde hangi konuların olması gerektiği, hangi konuların öğretim dışında bırakılacağı ve belirlenen içeriğin nasıl öğretileceği konuları siyasal dönemlere ve toplumsal koşullara göre değişiklik göstermektedir. Örneğin Cumhuriyetin kurulmasıyla birlikte nasıl bir birey yetiştirileceğiyle ilgili tartışmalar başlanmış ve buna yönelik olarak ders kitaplarında değişikliklere gidilmiştir. Tarih öğretimine yönelik olarak Çapa (2002)'ya göre Cumhuriyetin ilk yıllarında özellikle ilköğretim tarih eğitim programında 1924 ve 1926 yıllarında değişiklik yapıldığını ifade etmektedir. Değişiklikler sadece bununla sınırlı kalmamış tarih öğretimine yönelik 1930 yılında tarih öğretimine yönelik Türk Tarih Tezi çerçevesinde tarih öğretimine yönelik ilk ve ortaokullarda yeni kitaplar yazılıııştır. 1927-1928 yılında yürürlüğe konulan ve tüm ilkokullarda okutulan tarih dersi daha çok yeni ilan edilen Cumhuriyet rejiminin ön gördüğ̈ "Milli Tarih" anlayışını ön plana çıkartarak Türk tarihini yeni bir perspektifte ele almıştır. Söz konusu Tarih dersinde Türk tarihini anlatırken İslam tarihine hiç yer verilmezken; Osmanlı tarihi özetle aktarılmakta ve padişahlara yönelik yüceltici bilgiler kitaptan çıkartılmıştır. Bu bağlamda farklı siyasal dönemlerde tarih eğitimine yönelik farklı uygulamalara gidilmenin yanı sıra öğrencilere tarih bilincini kazandıracak öğretmenlerin kamuya alımında da farklı uygulamalara gidilmiştir.

KPSS 1999 yılında genel olarak memur almak amaciyla ilk olarak Devlet Memurluğu Sınavı (DMS) adı altında Öğrenci Seçme ve Yerleştirme Merkezi (ÖSYM) tarafından yapıldı. Daha sonra öğretmenlik 
alımını da içine alarak kapsamı genişletilmiş 2001 yılında Kurumlar için Memur Alım Sınavı (KMS) olarak; 2002 yılından bu yana ise KPSS adı altında ÖSYM tarafindan yapılmaya devam edilmiştir. Öğretmen alımına yönelik sınav formatı ise 2003 yılından bu yana genel yetenek- genel kültür ve eğitim bilimleri olmak üzere iki oturum şeklinde yapılmaktaydı. Ancak 2013 yllından itibaren Tarih Öğretmenliği de dâhil olmak üzere 15 farklı alanda olmak üzere kamuya öğretmen istihdamı sağlamak amacıyla Öğretmenlik Alan Bilgisi Testi (ÖABT) ÖSYM tarafından yapılmaya başlanmıştır. Kamuda öğretmen olmak isteyen aday genel kültür- genel yetenek- eğitim bilimleri ve alan sınavı olmak üzere üç sınavın ortalamasına göre değerlendirmeye tabi tutulmaktadır. Tarih Öğretmenlik Alan Bilgisi'ne yönelik toplamda 50 soru sorulmaktadır.Söz konusu bu soruların 40 tanesi (\%80) alan bilgisi; 10 tanesi(\%20) ise alan eğitimine yöneliktir 2013 KPSS Tarih öğretmenliği ÖABT'ndeki konular ve test içerisinde bulunan konuların ağırlığı ise Tablo 1.'de sunulmuştur.

\begin{tabular}{clcc} 
Tablo 1.Tarih Öğretmenliği KPSS Alan Bilgisi Testi Konuları, Yüzdelik ve Ağıllı̆̆ı & \\
\cline { 2 - 4 } Test Türü & \multicolumn{1}{c}{ Test İçeriği } & Yaklaşık Ağırlık Yüzdesi & Genel Yüzdesi \\
\hline & Tarih Metodu & 8 & \\
& Eski Çağ Tarihi & 4 & \\
& İslamiyet Öncesi Türk Tarihi & 10 & \multirow{2}{*}{80} \\
& Orta Çağ İslam Tarihi & 12 & \\
Alan Bilgisi Testi & Osmanlı Tarihi & 14 & \\
& Türkiye Cumhuriyeti Tarihi & 12 & 20 \\
& Genel Dünya Tarihi & 12 & \\
& XX. yy Türk ve Dünya Tarihi & 8 & \\
Alan Eğitimi Testi & & - & \\
\hline
\end{tabular}

Tablo.1. incelendiğinde alan derslerine yönelik soruların \% 80 oranında olduğu, alan eğitimine yönelik soruların ağırlığının ise \% 20 olduğu görülmektedir.

\section{Hedeflerin Sinıflaması}

Eğitimde hedef; Demirel (2011) tarafindan öğrenciye kazandırılmak üzere seçilen istendik özellikler; Ertürk (1982) tarafından yetiştirdiğimiz insanda bulunmasını uygun gördüğümüz eğitim yoluyla kazandırılabilir nitelikteki davranışlar, Senemoğlu (2010) tarafından ise bünyesinde gözlenebilir, ölçülebilir davranışları kapsayan özellikler olarak belirtilmiştir. Hedefler eğitim açısından önemlidir; çünkü nasıl bir insan yetiştirmeyi amaçladığımız/bireyleri niçin yetiştirmeliyiz ya da eğitimin amacı nedir sorularının cevabı hedeflerde bulur (Ertürk, 1982; Demirel, 2011; Sönmez, 2012). Yine eğitim sürecinin belirli bir tutarlılık içerisinde gerçekleşmesi öğretim sürecinin sağl1klı bir şekilde yürütülmesi ve geçerli ve güvenilir bir değerlendirmenin yapılmasında hedeflerin belirlenmesi ve sınıflanması oldukça önemlidir (Bümen, 2006). Anderson, Krathwohl, Airasian, Wittrock (2001)'a göre hedef ise; öğrenme sürecinde öğrencilere hangi bilgileri kazandıracağımız ve öğrenme süreci sonunda hangi bilgileri kazandırmak istediğimize yönelik bir çerçevedir. Forehand(2010)'a göre ise hedef bilme basamağından değerlendirme basamağına kadar hiyerarşik düzenlemede zihinsel süreçlerin düzenlemesine olanak sağlayan bir yapıdır.

Eğitimde hedeflerin nasıl belirleneceği, belirlenen hedeflerin zorluk/karmaşıklık düzeyinin nasıl sıralanacağı önemli bir problemdir. Bu problemin aşılmasında taksonomiler önemli bir yere sahiptir. Taksonomilere yönelik Türkiye'de ilk akla gelen taksonomi şekli Bloom tarafindan 1956 yılında geliştirilen "Eğitim Hedeflerinin Taksonomisi" olduğu söylenebilir. Ancak Ar1 (2011) tarafından yapılan çalışmada Bloom'un taksonomisi dışında SOLO taksonomisi ve Detmer tarafından geliştirilen taksonomilerin de olduğu belirtilse de bunların yaygınlık düzeyi Bloom Taksonomisi kadar olmamıştır. Ancak bazı ülkelerde Bloom Taksonomisinden daha fazla diğer taksonomilerin daha fazla tanınır olduğu ifade edilmektedir.

\section{Bloom'un bilişsel alan taksonomisi}

Bilişsel alan; bilme, hatırlama, düşünme, problem çözme, yaratma gibi aktiviteleri içeren bir kavram olarak Bloom (1956) tarafindan tanımlamaktadır. Taksonomi kavramı Sönmez (2012) tarafindan istendik davranışların birbirinin ön koşulu olacak şekilde basitten karmaşığa, kolaydan zora, somuttan soyuta, aşamalı sıralanması, Özçelik (2009) tarafından ise hedeflerin aşamalı sınıflaması olarak tarif edilmiştir. Bloom (1956) taksonomi kavramıyla sınıflama kavramı sıklıkla birbirlerinin yerine 
kullanılan kavramlar olmasına karşın bu iki kavram birbirinin yerine kullanımının yanlış olduğunu belirtmiştir. Çünkü taksonomi, bazı yapısal kuralları içerirken; sınıflama ise birçok keyfi unsurlar içerebilir. Yine taksonomi, terimler tarafindan temsil edilen gerçek fenomenlere karşılık gelecek şekilde inşa edilirken; sınıflamalarda ise böyle bir zorunluluk bulunmamaktadır.

Eğitimde belirlenen hedeflere yönelik olarak bilişsel, duyuşsal ve devinişsel olarak farklı sınıflamalar bulunmaktadır (Pickard, 2007; Demirel, 2011; Kablan, 2012). Bilişsel alana yönelik sınıflamalarla ilgili Sönmez (2012)'e göre farklı görüşlerden söz edilebilir. Bunlar; Bloom; Anderson, Krathwohl ve meslekdaşları; Tuckman; Williams; Hannah ve Michaels; Stahl ve Murphy; Romizowski başta olmak üzere ondokuz farklı bilişsel alan sınıflamasından bahsedilebilir. Bilişsel alana yönelik olarak birçok sınıflama olmasına rağmen; bu sınıflamalar içerisinde en fazla dikkat çeken ve farklı bölgelerde tanınır olan Bloom'un 1956 yılında geliştirdiği bilişsel alan sınıflaması olmuştur (Ertürk, 1982; Özçelik, 2009). Bloom (1956)'a göre taksonominin ortaya çıkma süreci 1948 yılında Boston'da Amerikan Psikoloji Derneği tarafindan yapılan bir toplantı sonucunda kararlaştırılmıştır. Söz konusu toplantıda öğretmenler, idareciler, müfettişler arasında iletişimi kolaylaştırmak; eğitim programının en temel bileşenlerinden biri olan eğitim sürecindeki hedeflerin teorik bir çatısını oluşturmak; eğitim araştırmalarının temelini oluşturan ve değerlendirme sürecinin başlangıç noktası olan hedeflerin sınıflandırılmasının gerekliliği sonucuna varılmıştır. Toplantıda 34 kişilik bir komisyon oluşturulmuş ve bu komisyona hedeflerin "bilişsel boyutu" yazma ve organize etme görevi verilmiştir. Toplantıda ilk olarak gündeme gelen sorun hedeflerin sınıflandırılıp sınıflandırılamayacağı sorunu olmuştur. Ancak bu sorun eğitim hedeflerinin davranış olarak sınıflandırılabileceği sonucuna ulaşılarak aşılmıştır. İkinci olarak ise taksonominin kullanılabilirliğine yönelik bir takım kaygılar gündeme gelmiştir. Bu kaygıların başında eğer öğretmen sadece taksonomide belirlenen hedefleri seçerlerse bu durumun öğretmenlerin düşünme ve planlama yönlerini olumsuz yönde etkileyeceği düşüncesi gelmektedir. Eğitim hedefleri ve alt hedefler belirginleştikçe bu kaygı da ortadan kalkmıştır. Krathwohl (2010)'a göre bilişsel alan sınıflamayla ilgili olarak 1949 yılında iki defa toplanılarak neler yapılacağıyla ilgili görüşmeler yapılmış, taksonomiyle ilgili yeni gelişmeler tartışılmıştır. 1951 yılında Chicago Amerikan Psikoloji Derneği tarafından yapılan sempozyumdaki bildiriler, eğitim uzmanları ve öğretmenlerin bilişsel alan sınıflamasına yönelik yorumları, eleştirileri değerlendirilmiş ve 1956 yılında Bloom, Engelhart, Furst, Hill ve Krathwohl tarafından bilişsel alanın sınıflandırılmasına yönelik el kitabı yayınlanmıştır.

Bloom ve arkadaşları tarafından geliştirilen taksonomi Krathwohl $(2002,2010)$ 'a göre her biri dikkatli bir şekilde tanımlanmış bilme, kavrama, uygulama, analiz, sentez, değerlendirme olmak üzere 6 kategoriden oluşturulmuştur. Taksonomide bilgi, kavrama, analiz, sentez kategorilerinin 3 üç alt kategorisi bulunurken; değerlendirme kategorisinde 2 alt kategori bulunmakta, uygulama basamağında ise alt kategori bulunmamaktadır. Söz konusu kategorilerin ilk üç basamağı olan bilme, kavrama ve uygulama basamakları alt seviyede düşünme becerilerini gerektirirken; analiz, sentez ve değerlendirme basamağ ise üst düzey düşünme becerilerini gerektiren kategoriler olarak bilinmektedir (Köğce ve Baki, 2009). Anderson (2005)'e göre kategoriler basitten karmaşığa; somuttan soyuta doğru hiyerarşik olarak gittikçe karmaşıklaşan bir yapıya sahiptir. Başlangıçta taksonomi kavramı eğitimde iş görenler arasında tam olarak ne anlam ifade ettiği anlaşılamadığından dolayı çok az ilgi görmüştür. Anderson ve Krathwohl (2002)'e göre taksonomi eğitimciler tarafından inceledikçe tanınırlığı artmış ve 22 farklı dile çevrilerek yaygınlık kazanmıştır.

\section{Yenilenmiş Bloom Taksonomisi}

Bloom ve meslektaşları tarafından bilişsel alana yönelik olarak geliştirilen taksonomi yaklaşık olarak 50 yıl etkililiğini devam ettirmiştir (Pickard, 2007). Ancak 1995- 2001 yılları arasında Bloom'un Taksonomisini revize etmek amacıyla; bilişsel psikoloji (3), eğitim programları ve öğretim (3) ve ölçme ve değerlendirme (2) alanlarında uzman toplam 8 eğitimci ve bir grup araştırmacı toplantılar düzenlemişler; David Krathwohl ve Lorin Anderson taksonominin revize edilmeye ihtiyacının olduğu konusunda hem fikir olarak, taksonominin revize edilmesine öncülük ettiler (Anderson, 2005; Krathwohl, 2002). Bloom'un taksonomisinin yenilenme gerekçesi olarak Bümen (2006)'e göre iki sebep ön plana çıkmaktadır. Bunlardan birincisi; eğitim alanında iş görenlerin dikkatlerini tekrar orijinal taksonomiye çekerek karşılaşılan tasarım, uygulama ve standartlardaki sorunlara çözüm üretmek; ikinci olarak ise $\mathrm{ABD}$ ve dünyanın farklı bölgelerindeki güncel bilgilerle taksonomiyi birleştirmektir. Anderson (2005)'a göre ise Bloom Taksonomisinin gözden geçirilme gerekçeleri ise; bilişsel psikoloji alanındaki gelişmeler ve bilişsel alan taksonomisinin geliştirildiği zamandan bu yana sayısızca 
araştırmaların yapılmış olmasıdır. Orijinal taksonominin sınırlılıklarını inceleyen Hasan, Naomee ve Bilkis (2013) taksonominin uygulanmasında birçok eğitimcinin bir takım problemlerle karşılaşmaktadır. Karmaşı davranışların basit bir şekilde tek yönlü olarak bilişsel süreçler şeklinde sıralanması varsayımı büyük bir hata olarak görülmektedir.

Bloom'un orijinal taksonomisinde Anderson ve Krathwohl'un öncülüğünde bir takım değişiklikler yapıldı. Bloom tarafından tek yönlü olarak oluşturulan tablo bilgi boyutu ve bilişsel süreç boyutunu içerecek şekilde iki yönlü olarak yeniden düzenlendi. Bloom tarafından tek yönlü olarak isim ve eylem boyutu tek bir çatı altında toplanıyorken; bu sınırlılık yenilenmiş taksonomide aşılmış oldu. Bilgi boyutunda belirlenen hedeflerin, sadece ad/isim kısmı yer alırken; bilişsel süreç boyutunda eylemsi/fiil kısmına da yer verildi. Çalışmalar sonucunda iki önemli nokta ön plana çıktı. Bunlardan birincisi bilgi boyutunu ifade eden kısım hedeflerde isim halinde bulunurken; bilişsel süreç boyutu ise eylemsi olarak ifade edildi (Tanık ve Saraçoğlu, 2011; Amer, 2006; Bümen, 2006; Köğce ve Baki, 2009). Orijinal taksonomi ile yenilenmiş Bloom Taksonomisi arasındaki değişiklikleri şu şekilde sıralanmaktadır:

1. Orijinal taksonomi tek boyutluyken; Yenilenmiş Bloom Taksonomisi bilgi ve bilişsel süreç boyutu olarak iki boyutlu olarak değiştirilmiştir. Orijinal taksonomide ad ve eylemsi kısmı tek bir boyut içerisinde değerlendirilirken; yenilenmiş taksonomide bilgi boyutu ad kısmında; eylemsi kısmı ise bilişsel süreç boyutunda değerlendirilmektedir (Pickard, 2007; Bümen, 2006).

2. Bilgi boyutu üç temel kategori yerine dört boyut içerir. Bunlardan üçü orijinal taksonomide olduğu gibi olgusal, kavramsal, işlemsel bilgi iken; yenilenmiş taksonomide öğrencinin üst bilişsel aktivitelerinin farkındalığını içeren üstbilişsel bilgi dördüncü boyut olarak eklenmiştir (Anderson, 2005). Yenilenmiş taksonomideki bilgi boyutu Tablo 2'de sunulmuştur.

Tablo 2. Yenilenmiş Bloom Taksonomisindeki Bilgi Boyutunun Yapısı

\begin{tabular}{ll}
\hline Bilgi Boyutu & Alt Boyutlar \\
\hline \multirow{2}{*}{ A. Olgusal Bilgi } & AA. Terimlerin bilgisi \\
& AB. Özel detay ve öğeler bilgisi \\
& BA. Sınıflama ve kategori bilgisi \\
B. Kavramsal Bilgi & BB. İlke ve genellemeler bilgisi \\
& BC. Teoriler, modeller ve yapılar bilgisi \\
& CA. Konuyla ilgili beceri ve işlem aşamaları bilgisi \\
C. İşlemsel Bilgi & CB. Konuyla ilgili teknik ve yöntemlerin bilgisi \\
& CC. Uygun yöntemlerin hangi durumlarda nasıll kullanacağına yönelik ölçüt bilgisi \\
& DA. Stratejik bilgi \\
D. Biliş Ötesi Bilgisi & DB. Bilişsel görevler hakkındaki bilgi \\
& DC. Bireyin kendine dönük biliş ve öğrenmeyle ilgili bilgisi \\
\hline
\end{tabular}

Krathwohl, 2002:214

3. Bilişsel Süreç boyutu ise; orijinal taksonomide 6 boyut üzerinde önemli değişiklikler yapılarak korunmuştur. Orijinal kategorideki üç kategorinin isimleri değiştirilirken (Bilgi yerine hatırlamakavrama yerine anlama-sentez yerine yaratma), iki tanesinin yerleri değiştirilmiştir (YaratmaDeğerlendirme boyutunun yerine konuldu) ancak isimleri korunmuştur; kullanılan tüm kategoriler isimlerine uygun olarak fiil formuna dönüştürülmüsstür (Eroğlu ve Kuzu, 2014; Bümen, 2006; Hasan, Naomee, Bilkis, 2013) .

4. Analiz, uygulama ve değerlendirme basamakları korunarak uygula, analiz et, değerlendir şeklinde fiilimsi formuna dönüştürüldü (Köğce va Baki, 2009; Amer, 2006; Anderson, 2006).

5. Uygulama Kategorisinin altına iki alt boyut (yürütme ve uygulama) eklenmiştir (Krathwohl, 2002; Bümen, 2006).

6. Orijinal taksonomide değerlendirme basamağı daha çok ana kategorilere dönük yapılırken; yenilenmiş taksonomide alt kategoriler daha ağırlıklı olarak kullanılmıştır (Tanık ve Saraçoğlu, 2011; Bümen, 2006) Bilişsel süreç boyut ve alt basamakları Tablo.3'de sunulmuştur.

Tablo 3. Revize Edilmiş Bloom Taksonomisindeki Bilişsel Süreç Boyutunun Yapısı

\begin{tabular}{ll}
\hline Bilişsel Süreç & Alt Basamakları \\
\hline \multirow{2}{*}{ 1. Hatırlama } & 1.1. Tanıma, Fark etme \\
& 1.2.Geri çağırma \\
2. Anlama & 2.1. Yorumlama \\
& 2.2. Örnekleme
\end{tabular}




\begin{tabular}{ll} 
& 2.3. Sinıflama \\
& 2.4. Özetleme \\
& 2.5. Çıkarım yapma \\
& 2.6. Karşıllaştırma \\
& 2.7. Açıllama \\
& 3.1. Yürütme \\
3. Uygulama & 4.1. Uygulama \\
& 4.2. Örgütıutleme \\
4. Analiz Etme & 4.3. Atıfta bulunma \\
& 5.1. Denetim yapma \\
5. Değerlendirme & 5.2. Eleştirme \\
& 6.1. Oluşturma \\
6. Yaratma & 6.2. Planlama \\
& 6.3. Üretme \\
\hline
\end{tabular}

Krathwohl, 2002:215'ten uyarlanarak hazırlanmıştır.

Bu tablolardan hareketle Anderson (2005)'a göre Yenilenmiş Bloom Taksonomisi bilişsel süreç olarak bilinen yatay boyut, bilgi boyutu olarak bilinen dikey boyut olmak üzere iki boyut şeklinde revize edilmiştir. Söz konusu durum Tablo.4'te sunulmuştur. Krathwohl (2002) Yenilenmiş Bloom Taksonomisini tablo 4'de şu şekilde özetlemektedir:

Tablo 4. Bilişsel Alan Taksonomi Tablosu

\begin{tabular}{|c|c|c|c|c|c|}
\hline \multirow{2}{*}{ Bilgi Boyutu } & \multicolumn{5}{|c|}{ Bilişsel Süreç Boyutu } \\
\hline & Hatırlama Anlama & Uygulama & Analiz Etme & Değerlendirme & Yaratma \\
\hline \multicolumn{6}{|l|}{ A. Olgusal Bilgi } \\
\hline \multicolumn{6}{|l|}{ B. Kavramsal Bilgi } \\
\hline \multicolumn{6}{|l|}{ C. İşlemsel Bilgi } \\
\hline D. Üstbilişsel Bilgi & & & & & \\
\hline
\end{tabular}

Yenilenmiş Bloom Taksonomisine yönelik yurt içinde ve yurt dışında birçok çalışmalar bulunmaktadır. Yurt içinde yapılan çalışmaların bazıları: Bümen (2006)'in Program Geliştirmede Bir Dönüm Noktası: Yenilenmiş Bloom Taksonomisi adlı çalışması, Tanık ve Saraçoğlu (2011)'nun Fen Ve Teknoloji Dersi Yazılı Sorularının Yenilenmiş Bloom Taksonomisi'ne Göre İncelenmesi adlı çalışması, Eroğlu ve Kuzu (2014)'nun Türkçe Ders Kitaplarındaki Dilbilgisi Kazanımlarının Ve Sorularının Yenilenmiş Bloom Taksonomisine Göre Değerlendirilmesi adlı çalışması, Köğce ve Baki (2009)'nin Yazılı Sınav Soruları İle Öğrenci Seçme Sınavı Sorularının Yenilenmiş Bloom Taksonomisine Göre Karşılaştırılması adlı çalışması sıralanabilir. Yurt dışında yapılan çalışmaların bir kısmı ise Bloom Taksonomisinin revize edilmesine yönelik Krathwohl (2002)'un; hedefler değerlendirmeler ve eğitimin geliştirilmesine yönelik Anderson (2005)'un; Bloom'un Yenilenmiş Taksonomisinin yansımalarına yönelik Amer (2006)'in; Yenilenmiş Bloom Taksonomisine yönelik Pickard (2007)'ın çalışmaları sıralanabilir. Bu çalışmalar içinde Türkiye'de oldukça önemli ve yaygın olan KPSS' yönelik bir çalışmanın olmaması bir eksiklik olarak düşünülebilir. Bu çalışma söz konusu eksikliği gidermek ve bir başlangıç oluşturmak amacını taşımaktadır.

Yenilenmiş Bloom Taksonomisine yönelik yurt içinde ve yurt dışında birçok çalışmalar bulunmaktadır. Yurt içinde yapılan çalışmalara Bümen (2006)'in Program Geliştirmede Bir Dönüm Noktası: Yenilenmiş Bloom Taksonomisi; Tanık ve Saraçoğlu (2011)'nun Fen ve Teknoloji Dersi Yazılı Sorularının Yenilenmiş Bloom Taksonomisi'ne Göre İncelenmesi; Eroğlu ve Kuzu (2014)'nun Türkçe Ders Kitaplarındaki Dilbilgisi Kazanımlarının Ve Sorularının Yenilenmiş Bloom Taksonomisine Göre Değerlendirilmesi; Köğce ve Baki (2009)'nin Yazılı Sınav Soruları İle Öss Sınavı Sorularının Yenilenmiş Bloom Taksonomisine Göre Karşılaştırılması örnek olarak verilebilir. Yurt dışında yapılan çalışmaların bir kısmı ise Bloom Taksonomisinin revize edilmesine yönelik Krathwohl (2002)'un; hedefler değerlendirmeler ve eğitimin geliştirilmesine yönelik Anderson (2005)'un; Bloom'un Yenilenmiş Taksonomisinin yansımalarına yönelik Amer (2006)'in; Yenilenmiş Bloom Taksonomisine yönelik Pickard (2007)'ın çalışmaları sıralanabilir. Türkiye'de öğretmen seçiminde önemli bir yer tutan KPSS'de sorulan soruların niteliği öğretmen seçiminde,öğretmen adaylarının bilgi birikimini ölçmede önemli bir yeri olduğu düşünülmektedir. Özellikle Türkiye'de oldukça önemli ve yaygın olan KPSS'ye 
yönelik bir çalışmanın olmaması bir eksiklik olarak düşünülebilir. Bu çalışma söz konusu eksikliği gidermek ve bir başlangıç oluşturmak amacını taşımaktadır.

\section{Araştırmanın Amacı}

Bu araştırmada 2013 yılındaki KPSS Tarih Öğretmenliği Alan Bilgisi Testindeki soruların Yenilenmiş Bloom Taksonomisi bilişsel alanda yer alan bilgi ve bilişsel boyutundaki dağılımların analizini ortaya çıkarmak amaçlamaktadır. Bu bağlamda KPSS 2013 Tarih Öğretmenliği Alan Bilgisi Testinde sorulan soruların Yenilenmiş Bloom Taksonomisi analiz sonucuna göre dağılımı nasıldır? sorusuna cevap aranmaktadır.

\section{YÖNTEM}

$\mathrm{Bu}$ bölümde araştırmanın modeli, evren ve örneklemi, veri toplama araçları, verilerin analizinde kullanılan istatistiksel teknikler açıklanmıştır.

\section{Araştırmanın Modeli}

$\mathrm{Bu}$ araştırmada nitel araştırma yaklaşımı kullanılmış; yöntem olarak ise doküman analizi yöntemi kullanılmıştır. Doküman analizi; olgu ve olaylar hakkında bilgi içeren yazılı materyallerin analizini kapsamakta ve eğitimle ilgili araştırmalarda tek başına yöntem olarak kullanılabileceği ifade eder (Yıldırım ve Şimşek, 2010).

\section{Veri toplama aracı}

Araştırmada veri toplama aracı olarak KPSS 2013 Tarih Öğretmenliği Alan Bilgisi Testi sorularını içeren yazılı dokümanlar kullanılmıştır.

\section{Verilerin analizi}

Araştırmada öncelikli olarak KPSS 2013 Tarih Öğretmenliği Alan Bilgisi Testinde yer alan sorular Yenilenmiş Bloom Taksonomisine göre ele alınarak incelenmiştir. Veri analizi aşamasında yenilenmiş taksonomiye yönelik bilgi ve bilişsel süreç boyutunun yer aldığı Krathwohl (2002) tarafından oluşturulan tablo kullanılmıştır. Sorular incelenerek soruların her birinin öncelikli olarak hangi bilişsel süreç boyutu içerinde yer aldığı belirlenmiş; daha sonra bilgi boyutu olarak hangi basamak içerinde yer aldığ tespit edilmiştir. Soru içerisinde ad kısmı bilgi boyutuna; eylemsi kısmı ise bilişsel süreç boyutuna yerleştirilmiştir. Testteki sorular bilişsel süreç boyutu bağlamında aynı anda birden fazla boyutu işaret ettiği durumlarda ise Bekdemir ve Selim (2008)'in görüşleri doğrultusunda daha üst düzey olan kategoriye yerleştirilmiştir. Sonraki aşamada ise 50 Tarih sorusundan elde edilen bulgulara göre Krathwohl (2002) tarafindan oluşturulan tabloya yerleştirilmiştir. Testte yer alan sorular, Yenilenmiş Bloom Taksonomisinin, bilgi boyutunun ve bilişsel süreç boyutunu hangi basamağında yer aldığı tabloya göre tespit edilmiştir. Daha sonra, testlerin dağılımlarının frekans ve yüzdelikleri ortaya çıkartılmıştır. KPSS Tarih Öğretmenliği Alan Bilgisi Testine yönelik soruların analizinin nasıl yapıldığına ilişkin örnekler aşağıda sunulmuştur.

Soru: "Tarih Dersinde Çevre İncelemeleri” adlı eser aşağıdakilerden hangisine aittir?
A) Muallim Cevdet İnançalp
B) Mustafa Çağatay Uluçay
C) İsmail Hakkı Baltacıŏglu
D) Faik Reşit Unat
E) Ahmet Refik Altınay

Analiz işlemi: Tarih Dersinde Çevre İncelemeleri adlı eser bilgi boyutu olarak olgusal bilgiyi işaret etmektedir. Olgusal bilgi boyutunun alt basamağ 1 olarak ise belli bir terim/sembol işaret etmemekte; öğrencinin karşılaştığı bir probleme çözüm üretebilecek temel öğeyi içerdiği için özel detay ve öğeler bilgisini ifade etmektedir. Sorunun... aşağıdakilerden hangisine aittir? kısmı ise bilişsel süreç boyutunu işaret etmektedir. Burada istenen seçeneklerde yer alan yazarlardan hangisinin söz konusu eseri yazdığının öğretmen adaylarından hatırlaması istenmektedir. $\mathrm{Bu}$ ise hatırlama kategorisinde anımsama(geri çağırma) alt basamağını göstermektedir. Hedefleri tabloya yerleştirilmesinde ise üç aşamalı bir yol izlenmiştir:

1. Öncelikle KPSS Tarih Öğretmenliği Alan Bilgisi Testi’ndeki sorunun numarasının yazılması (Örneğin, 25. soru) 
2. Bilişsel süreç boyutu Tablo.4'de belirtildiği şekilde rakamlarının yazılması (Örneğin; İkinci boyut: Anlama; alt basamağı özetleme: 2.4 şeklinde).

3. Bilgi boyutunda ise Tablo.3'deki gibi bilgi boyutunun alt basamaklarını ifade eden harflerin yazılması(AA, CA gibi). Örneğin; Tablo.6'da bulunan 25-1.2.AB kısaltması; 25.soru; bilişsel süreç boyutu olarak (1) "hatırlama"; hatırlamanın alt kategori olarak (2) anımsama; bilgi boyutu olarak ise (A) olgusal bilgi; bilgi boyutunun alt basamağı olarak ise (B) terimler bilgisini ifade etmektedir.

İkinci örnek ise KPSS Tarih Öğretmenliği Alan Bilgisi Testi'ndeki 29.sorunun analizi şu şekilde yapılmışıtır:

Türkiye İktisat Kongresi'nde ulusal ve tam bağımsız bir ekonomiyi esas alan öneriler ön plana çıkmıştır. İktisat Kongresi'nde yapılan aşağıdaki önerilerden hangisinin bu doğrultuda olduğu söylenemez?

A) Kambiyo merkezleri ile tahvil borsalarının millîleştirilmesi

B) Tarım dışındaki işçiler için günlük çalışma süresinin 8 saat olması

C) Yerli sanayiyi koruyucu önlemler alınması

D) Kendi limanlarımızda bayrağımızı taşıyan gemilerin ticaret yapması

E) Tekel hakkı tanınmış yabancı sermayenin kaldırılması

Tablo.5. Tarih Öğretmenliği ÖABT 29. Sorunun Yenilenmiş Bloom Taksonomisine Göre Analizi

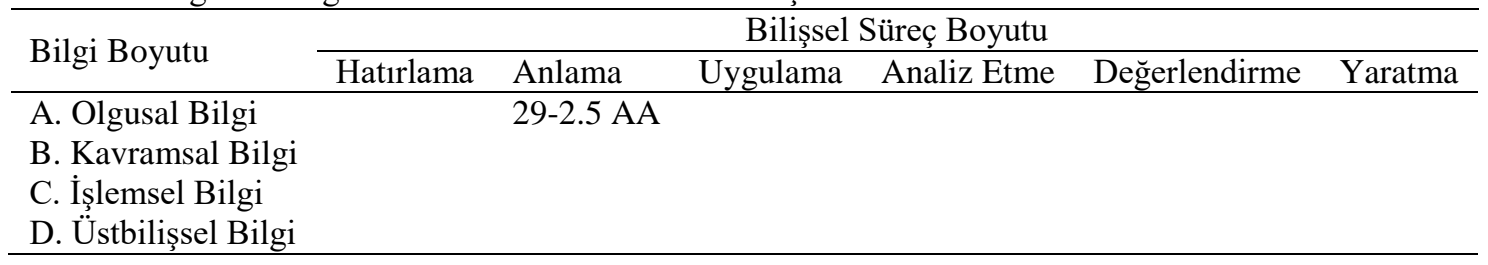

Söz konusu soru Tablo.5'de 29-2.5.AA şeklinde yer almaktadır. Soruda Türkiye İktisat Kongresi'nde ulusal ve tam bağımsız bir ekonomiyi esas alan öneriler üzerinde durmaktadır. Bu soru öğretmen adaylarının Türkiye İktisat Kongresi'ndeki önerilerden sonuç çıkarmalarını öngörmektedir. Bundan dolayı bilişsel süreç boyutu olarak "anlama" basamağı; anlama boyutunun alt basamağı olarak ise "sonuç çıkarma" yı işaret etmektedir. Bilgi boyutu olarak ise öğretmen adaylarından karşılaştıkları bir problem durumunu çözebilecekleri temel öğeyi (Türkiye İktisat Kongresi) işaret ettiği için "olgusal bilgi"; bilgi boyutunun alt basamağı olarak ise terimler bilgisi bağlamında "teknik terimler bilgisi" ni işaret etmektedir.

\section{Araştırmanın Güvenirliği}

Araştırmanın güvenirliğini sağlamak için ise Hubermann ve Miles (1994) tarafindan önerilen

$$
\text { Güvenirlik }=\frac{\text { Görüş Birliği }}{\text { Görüş Birliği+ Görü̈ş Ayrllı̆̆g }} \text { kullanılmıştır. }
$$

KPSS' de çıkan Tarih Öğretmenliği Alan Bilgisi Testi soruları Krathwohl (2002) tarafindan oluşturulan Yenilenmiş Bloom Taksonomisi tablosuna 2 farklı araştırmacı tarafından söz konusu sorular okunup; ilgili tabloya yerleştirilmesi istenmiştir. Araştırmacıların sorulara yönelik analizleri sonucunda \%81'lik bir güvenirlik sonucuna ulaşılmıştır. Bir araştırmanın güvenirliği için \%70 'lik bir sonucun yeterli olduğunu ifade eden Hubermann ve Miles (1994)'a göre çıkan sonucun bu çalışmanın güvenilirliğin için yeterli düzeyde olduğu kabul edilerek analiz aşamasına geçilmiştir.

\section{BULGULAR}

Araştırmanın bu kısmında 2013 yılında KPSS Tarih Öğretmenliği Alan Bilgisi Testindeki 50 sorunun yenilenmiş Bloom Taksonomisinin bilgi ve bilişsel süreç boyutuna göre yerleştirilmiştir. KPSS Tarih Öğretmenliği Alan Bilgisi Testindeki soruların Bilgi ve Bilişsel Süreç Boyutuna Yönelik kodlamalar Tablo.6' da sunulmuştur. 
Tablo.6. KPSS Tarih Öğretmenliği Alan Bilgisi Testindeki soruların Bilgi ve Bilişsel Süreç Boyutuna Yönelik Tablo

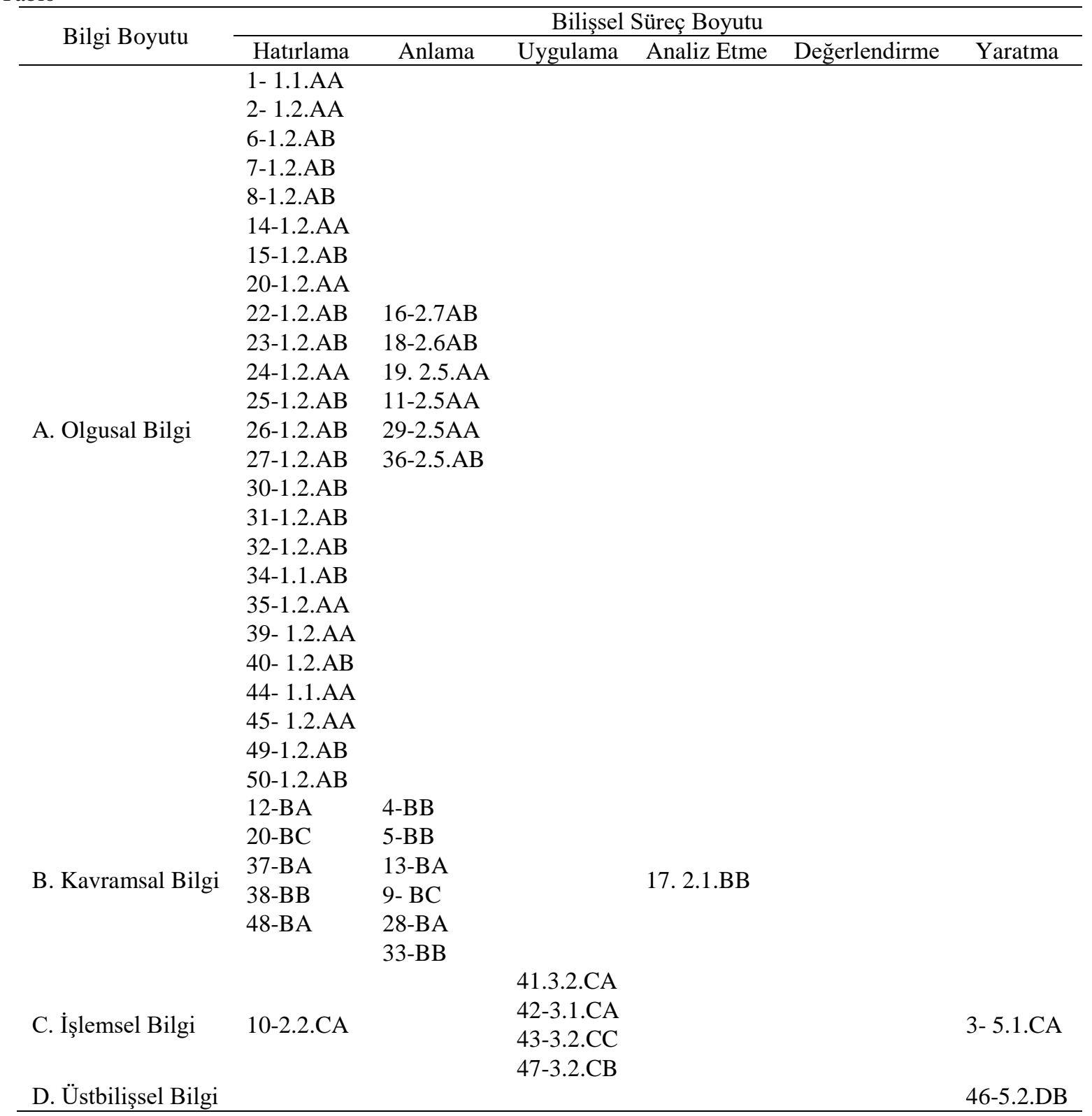

Tablo.6 incelendiğinde soruların bilişsel süreç boyutu bağlamında hatıllama alt boyutuna yönelik 31 soru(\% 62); anlama alt boyutuna yönelik 12 soru (\%24);uygulama alt boyutuna yönelik 4 soru (\%8);analiz etme alt boyutuna yönelik 1 soru (\%2); yaratma alt boyutuna yönelik 2 soru (\%4) olduğu görülmektedir. Yine bilgi boyutunda alt boyutlar olarak olgusal bilgiye yönelik 31 soru(\%62);

kavramsal bilgiye yönelik 12 soru(\%24);işlemsel bilgiye yönelik 6 soru(\%12); üst bilişsel bilgiye yönelik 1(\%2) soru sorulduğu görülmektedir.

Tarih öğretmenliği alan bilgisi testindeki soruların bilgi boyutları ve bilişsel süreç boyutları birlikte değerlendirmesi Tablo.7'de verilmiş̧ir. 
Tablo 7. Tarih Öğretmenliği Alan Bilgisi Testindeki soruların Bilgi-bilişsel süreç boyutlarının Yenilenmiş Bloom Taksonomisine Göre Dağılımı

\begin{tabular}{lcccccccccccc}
\hline & \multicolumn{10}{c}{ Bilişsel Süreç Boyutu } \\
\cline { 2 - 13 } Bilgi Boyutları & \multicolumn{1}{c}{ Hatırlama } & \multicolumn{1}{c}{ Anlama } & \multicolumn{1}{c}{ Uygulama } & Analiz Etme & Değerlendirme & Yaratma \\
& $f$ & $\%$ & $f$ & $\%$ & $f$ & $\%$ & $f$ & $\%$ & $f$ & $\%$ & $f$ & $\%$ \\
\hline A. Olgusal Bilgi & 25 & 50 & 6 & 12 & - & & & & - & & - \\
B. Kavramsal Bilgi & 5 & 10 & 6 & 12 & - & & 1 & 2 & - & - & \\
C. İşlemsel Bilgi & 1 & 2 & - & & 4 & 8 & & & - & 1 & 2 \\
D. Üstbilişsel Bilgi & - & & - & & & & & & 1 & 2 \\
\hline
\end{tabular}

Tablo.7 incelendiğinde 2013 KPSS Tarih Öğretmenliği Alan Bilgisi Testindeki sorularının bilgi-bilişsel süreç boyutlarına birlikte bakıldığında bilişsel süreç boyutu olarak hatırlamaya yönelik 31 soru bulunmaktadır.Bu soruların bilgi boyutu bağlamında 25 tanesi (\%50) olgusal bilgi alt boyutu; 5 tanesi (\%10) kavramsal bilgi alt boyutu; 1 tanesi(\%2) işlemsel bilgi alt boyutundadır. Yine bilişsel süreç boyutu olarak anlamaya yönelik 12 soru bulunmakta olup; bilgi boyutları olarak 6 tanesi (\%12) olgusal bilgi alt boyutu; 6 tanesi(\%12) kavramsal bilgi alt boyutundadır. Uygulama bilişsel süreci boyutuna ilişkin 4 soru(\%8) bilgi boyutu olarak işlemsel bilgi alt boyutundadır. Analiz etmeye yönelik 1 soru (\%2) bilgi boyutu olarak kavramsal bilgi alt boyutundadır.Yaratma bilişsel süreç boyutu olarak 1 soru (\%2) işlemsel bilgi alt boyutu; 1 soru (\%2) ise üst bilişsel bilgi alt boyutundadır.

\section{TARTIŞMA ve SONUÇ}

Tarih Öğretmenliğine yönelik 2013 yılında yapılan KPSS'deki soruların yenilenmiş Bloom taksonomisinin bilgi boyutu ve bilişsel süreç boyutuna göre incelendiğinde soruların yarısından fazlasının (31 soru) bilişsel süreç boyutunun en alt basamağı olan "hatırlama" kısmına yönelik olması, üst düzey düşünme becerilerini ölçen uygulama, analiz ve değerlendirme basamaklarının olmaması bir eksiklik olarak değerlendirilebilir. Yine "hatırlama" boyutuna yönelik oldukça fazla soru olmasına rağmen; analiz, değerlendirme kısmındaki bilişsel süreçlere yönelik sadece bir tane sorunun olması bilişsel süreç boyutuyla ilgili soru dağılımında oransal açıdan değerlendirildiğinde de bir uyumsuzluğun olduğu söylenebilir. Tarih Öğretmenliği'ne yönelik sorulardan anlama, uygulama, değerlendirme ve yaratmaya yönelik soruların tümünün toplamı "hatırlama" yönelik bilişsel süreç boyutundan daha az olması bir çelişki olarak görülmektedir.

$\mathrm{Bu}$ çalışma Tarih Öğretmenliğine yönelik Alan Bilgisi Testi bağlamında ilk olma özelliği taşıdığından dolayı farklı alan bilgisi testiyle karşılaştırma imkânı bulunmamaktadır. Bundan dolayı Yenilenmiş Bloom Taksonomisine göre farklı analizlerin sonucu bu çalışmada elde edilen sonuçlar karşılaştırıldığında Dindar ve Demir(2006)'in beşinci sınıf Fen Bilgisi dersi öğretmenlerinin sınav sorularının ağırlıklı olarak Bilme (Hatırlama) boyutunda olduğuna yönelik sonucu bu araştırmanın bulgularıyla örtüşmektedir. Yine Eroğlu ve Kuzu (2014)'nun Türkçe Dersi (6., 7. ve 8. sınıf) Öğrenci Çalışma Kitaplarında yer alan dil bilgisi sorularının ve öğretmen kılavuz kitabında yer alan dilbilgisi kazanımlarının Yenilenmiş Bloom Taksonomisi'nin bilişsel alan basamaklarına göre dağılımı konusunda bilişsel alan basamağı olarak alt seviyedeki soruların fazla; üst seviyeyi sorgulayan soruların azlığına dikkat çekilmektedir. Söz konusu bulgular bu araştırma sürecindeki bulgularla benzerlik göstermektedir. Yine Hasan, Naomee, Bilkis (2013) tarafından ortaokul Sosyal Bilgiler sınav sorularına yönelik analizde alt seviyedeki düşünme becerilerine yönelik soru sayılarının fazla; analiz, değerlendirme ve yaratma seviyesindeki soru sayılarının ya hiç olmadığı ya da çok az sınırlı sayıda soruların sorulduğu ifade edilmektedir. Tanık ve Saraçoğlu (2011) tarafından yapılan Fen Ve Teknoloji Dersi Yazılı Sorularının Yenilenmiş Bloom Taksonomisi'ne Göre İncelenmesi konulu çalışmada öğretmenlerin öğrencileri üst düzey düşünmeye sevk edecek nitelikte olmadığı, öğrencilerin hatırlama becerilerini ölçme üzerine yoğunlaştı̆̆ sonuçlarına ulaşılmıştır.

Tarih Öğretmenliği'ne yönelik alan bilgisi testi soruları incelendiğinde bu sınavda başarılı olan öğretmen adayları yapılandırmacılık yaklaşımını benimseyen Milli Eğitim Bakanlığı'nda görev alacaklardır. Tarih öğretmen adaylarının alan bilgisi yeterliliğini ölçen sınavda sorulan soruların yapılandırmacılıkta en fazla kullanılan uygulama, analiz etme, değerlendirmeye yönelik soruların oldukça az olması bir çelişki olarak değerlendirilebilir. Çünkü öğretmenden istenilen özellikler daha üst 
düzey beceriler gerektirirken özellikler iken yapılan sınavda ise alt düzey düşünme becerileri gerektiren sorular sorulmaktadır.

KPSS Tarih Öğretmenliği Alan Bilgisi Sınavı soruları incelendiğinde ağırlıklı olarak bilgi boyutu bağlamında olgusal bilginin alt basamakları olan terimler bilgisi ile özel ayrıntı ve öğeler bilgisinde oluşmaktadır. Kavramsal bilgi ve işlemsel bilgiyi ölçmeye yönelik soruların sınırlı sayıda; üst bilişsel bilgininin ortaya çıkartılmasına yönelik ise sadece bir sorunun sorulmasının bir sınırlılık olduğu düşünülmektedir. Özellikle daha karmaşık bilgilerin ölçüldüğü, bireyin kendi biliş stratejilerinin farkında olduğu üst bilişsel bilgiye yönelik sorularının sayısının arttırılmasının öğretmenliğin niteliğini arttırma bağlamında etkili olacağı düşünülmektedir. Yine bu bağlamda Tarih öğretmen adaylarının sadece bir takım bilgileri hatırlamalarının ağırlıklı olarak ölçüldüğü söz konusu sınavda; hatırlanılan bu bilgilerin nasıl öğretileceğine yönelik bilgi ve becerileri sorgulayacak soruların da sorulmasının faydalı olacağı düşünülmektedir. Bu doğrultuda özellikle 2013 yılından itibaren kamuya daha nitelikli öğretmen almak için uygulamaya konan tarih öğretmenliği alan bilgisi testi sorularının amacına hizmet etmesi için soru dağılımlarının Yenilenmiş Bloom Taksonomisi göz önünde bulundurarak dengeli bir şekilde dağılımının sağlanması gerekir.

\section{KAYNAKLAR}

Alaslan, F., Şimşek, A., \& Çamdeviren, Ş. (2012). Türk maarif (eğitim) şûralarında tarih eğitimi. Kalem Eğitim ve Insan Bilimleri Dergisi, 2(2), 189-225.

Amer, A. (2006). Reflections on Bloom's revised taxonomy. Electronic Journal Of Research In Educational Psychology, 4(1), 213-230.

Anderson, L. W. (2005). Objectives Evaluation and The Ġmprovement of Education. Studies in Educational Evaluation, 31 (2), 102-113.

Anderson, L. W., Krathwohl, D. R., Airasian, P. W., Cruikshank, K. A., Mayer, R. E., Pintrich, P. R., Wittrock, M. C. (2001). Öğrenme Öğretim ve Değerlendirme ile İlgili Bir Sınıflama: Bloom'un Eğitimin Hedefleri İle İlgili Sınıflamasının Güncelleştirilmiş Biçimi. (Çev. Özçelik, D. A. 2014, Anderson, L. W., Krathwohl, D. R., Airasian, P. W., Cruikshank, K. A., Mayer, R. E., Pintrich, P. R., Raths, J. ve Wittrock, M. C. Eds. 2. Bask1). Ankara: Pegem Akademi.

Aslan, E. (2010). Neden tarih öğretiyoruz? Buca Eğitim Fakültesi Dergisi, 20, 162-173

Aslan, E. (2011). Türkiye Cumhuriyetil’nin ilkokullarda izlediği ilköğretim programı:"1924 ilk mektepler müfredat programı". Ilköğretim Online, 10(2). 717-734

Bekdemir, M., Selim, Y. (2008). Revize edilmiş bloom taksonomisi ve cebir öğrenme alanı örneğinde uygulaması. Erzincan Eğitim Fakültesi Dergisi, 10(2), 185-196

Bloom, B.S., Engelhart, M.D, Furst, E.J, Hill, W.H., and Krathwohl, D.R. (1956). Taxonomy Of Educational Objectives. Book I: Cognitive Domain. U.S: Longman.

Bümen, N. T. (2006). Program geliştirmede bir dönüm noktası: yenilenmiş bloom taksonomisi. Eğitim ve Bilim, $32(142)$.

Çapa,M.(2002). Cumhuriyet'in ilk yıllarında tarih öğretimi. Ankara Üniversitesi Türk İnklâp Tarihi Enstitüsü Atatürk Yolu Dergisi, (29-30). 39-55

Demirel, Ö.(2011). Kuramdan uygulamaya eğitimde program geliştirme. Ankara: Pegem Akademi

Dindar, H. ve Demir, M. (2006). Beşinci sınıf oğretmenlerinin fen bilgisi dersi sınav sorularının Bloom taksonomisine gore değerlendirilmesi, GU, Gazi Eğitim Fakültesi Dergisi, 26(3), 87-96.

Eroğlu,D.,Kuzu, T. S. (2014). Türkçe Ders Kitaplarındaki Dilbilgisi Kazanımlarının Ve Sorularının Yenilenmiş Bloom Taksonomisine Göre Değerlendirilmesi. Başkent University Journal Of Education, 1(1).

Ertürk, S. (1982). Ĕgitimde program gelişstirme. Ankara: Meteksan.

Forehand, M. (2010). Bloom"s Taxonomy. Emerging Perspectives on Learning, Teaching and Technology. (ebook) $41-47$.

Gutek, G. L. (2006). Eğitime Felsefi ve İdeolojik Yaklaşımlar, (Çev. Nesrin Kale).Ankara:Ütopya Yayınları.

Hasan, M., Naomee, I., \& Bilkis, R.(2013). Reflection of bloom's revised taxonomy in the social science questions of secondary school certıficate examınation. The International of Journal Social Sciences (TIJOSS). 14(1), 47-56.

Miles, M. B., \& Huberman, A. M. (1994). Qualitative data analysis: An expanded sourcebook. 1994. Beverly Hills: Sage Publications.

Kablan, Z.(2012).Hedef belirleme: bilişsel, duyuşsal ve devinişsel alanlar.(Ed.Hasan Şeker). Eğitimde program geliştirme kavramlar ve yaklaşımlar. Ankara: Anı Yayıncılık.

Köğce, D., Baki, A. (2009). Matematik öğretmenlerinin yazılı sınav soruları ile ÖSS sınavlarında sorulan matematik sorularının Bloom taksonomisine göre karşılaştırılması. Pamukkale Üniversitesi Eğitim Fakültesi Dergisi, 26, 70-80. 
Anderson, L. W., \& Krathwohl, D. R. (2002). A taxonomy for teaching, learning, and assessing.Newyork:Longman

Krathwohl, D.R. (2002). A revision of Bloom's taxonomy: an overwiew. Theory into Practice. 41,4, $212-218$.

Miles, M. B.,Huberman, A. M. (1994). Qualitative data analysis: an expanded sourcebook. California. : SAGE Publications.

Okur, Y., Genç, İ., Özcan,T., Yurtbay, M ve Sever, A.(2014).Orta öğretim 9.Sınıf Ders Kitabı. Ankara: MEB Yayınları

Özçelik, D.A. (2009). Ĕgitim programları ve öğretim. Ankara: Pegem Akademi

Pickard, M.J. (2007). The new Bloom's taxonomy: An overview for family and consumer sciences. Journal of Family and Consumer Sciences Education, 25(1), 45-55.

Senemoğlu, N.(2010). Gelişim, öğrenme ve öğretim. Ankara: Pegem Akademi

Sönmez, V.(2012). Program geliştirmede öğretmen el kitabı. Ankara: Anı Yayıncılık.

Şıvgın, H. (2009). Ulusal tarih eğitiminin kimlik gelişimindeki önemi. Gazi Akademik Bakış, (04), 35-53.

Tanık, N.,Saraçoğlu, S. (2011). Fen ve teknoloji dersi yazılı sorularının yenilenmiş bloom taksonomisi’ne göre incelenmesi. TÜBAV Bilim Dergisi, 4(4), 235-246. 